\title{
Willfried Spohn
}

Geschichte und Emanzipation

Bahros Beitrag zur Sozialismus-Diskussion

\section{Einleitung}

Rudolf Bahros Buch: Die Alternative, Zur Kritik des real existierenden Sozialismus (1) ist ohne Zweifel das wichtigste marxistische Werk der Nachkriegszeit aus den osteuropäischen Ländern und verbindet geistige Radikalität und persönlichen Mut eines kommunistischen Ketzers. Die hier entworfene Theorie sozialer Emanzipation, die daraus grundsätzliche Kritik an den sogenannten sozialistischen Übergangsgesellschaften und das hierin begründete kommunistische Aktionsprogramm einer emanzipatorischen Kulturrevolution haben nicht nur prinzipielle Bedeutung für die osteuropäische Diskussion um eine kommunistische Alternative in den sozialistischen Ländern, sondern aufgrund ihrer allgemein-geschichtlichen Spannweite auch für die westeuropäische Sozialismus-Diskussion. Bahros Theorie sozialer Emanzipation knuipft an das allgemeine Zentrum der Marx-Engelsschen materialistischen Geschichtstheorie: die Entstehung von Klassengesellschaft und Staat durch die naturwüchsige gesellschaftliche Arbeitsteilung an und rückt erneut als Ziel sozialer Emanzipation die Aufhebung dieser Arbeitsteilung in denMittelpunkt. Im Vergleich zu diesem Kommunismus erweisen sich die Länder des real existierenden Sozialismus in der Tat als staatlich-bürokratisch organisierte Klassengesellschaften, die wohl das Privateigentum durch das Staatseigentum an den gesellschaftlichen Bedingungen der Produktion ersetzt, aber dadurch die überkommene gesellschaftliche Arbeitsteilung als eigentliche Grundlage sozialer Herrschaft noch nicht angetastet haben. Orientiert an dem Ziel sozialer Emanzipation als Aufhebung jeglicher sozialer Herrschaft wird als Alternative ein Aktionsprogramm der Kulturrevolution entworfen, das die Transformation der gesellschaftlichen Verhältnisse in den sozialistischen Ländern zur Verwirklichung der sozialen Emanzipation in ihren ökonomischen, politischen und individuellen Elementen umreißt.

Aufgrund dieses umfassenden Charakters der Bahroschen Analyse läßt sie sich keineswegs auf eine rein interne kommunistische Querele in den osteuropäischen Ländern reduzieren, sondern intergriert die zentralen realanalytischen Elemente der Sozialismus-Diskussion einer jeden sozialistisch-kommunistischen Bewegung in den entwickelten Industriegesellschaften. Die materiellen Anstöße seiner geschichtsma-

1 R. Bahro: Die Alternative, Zur Kritik des real existierenden Sozialismus, Köln, Frankfurt/M. 1977. Die Seitenangaben im Text beziehen sich, soweit nicht anders vermerkt, auf diese Ausgabe. Vg1. auch die Kurzfassung in : ders., Eine Dokumentation, Frankfurt/M. 1977, S. $9-55$ 
terialistischen Emanzipationstheorie und der daraus folgenden radikálen Kritik des real existierenden Sozialismus wie der kommunistischen Alternative einer grundsätzlichen Kulturrevolution liegen, wie er selbst sagt (2), in den militärisch-politischen Konflikten innerhalb des sozialistischen Lagers, in den sozialen Widersprïchen der DDR, der Diskrepanz zwischen Anspruch und Wirklichkeit staatlich-kommunistischer Politik, der militärischen Zerschlagung des Prager Frühlings 1968 durch die Sowjetunion, dem Ausbruch der Arbeiterkämpfe gegen die kommunistische Staatspartei in Polen 1970 wie auch in der chinesischen Kulturrevolution, aber auch außerhalb des sozialistischen Lagers in dem Aufschwung der antikapitalistischen Bewegungen von Arbeitern und Intellektuellen in Westeuropa und der in diesem klassenpolitischen Rahmen zunehmenden Loslösung der eurokommunistischen Parteien von der sowjetischen Außenpolitik. Aber Bahro ist nicht identisch mit den verschiedenen Oppositionsströmungen in Osteuropa, weder mit der Bürgerrechtsbewegung noch mit dem Manifest des Bundes demokratischer Kommunisten, er ist auch nicht identisch mit den verschiedenen sozialistisch-kommunistischen Strömungen in Westeuropa, weder mit dem Eurokomminismus noch mit dem Trotzkismus oder Linkskommunismus. Er erweist sich als unabhängiger Denker, läßt sich als Theoretiker nicht vereinnahmen, nimmt die emanzipatorischen Elemente der jeweiligen sozialistisch-kommunistischen Bewegungen in sich auf und ist zugleich wenn auch zumeist implizit scharfer Kritiker ihrer jeweiligen traditionell-konservativen Fixierungen. Gerade deshalb könnte er einen eminenten Impuls für die westeuropäische und namentlich die westdeutsche Sozialismus-Diskussion darstellen.

Die westdeutsche Sozialismus-Diskussion hat einen solchen Impuls dringend nötig (3). Im Kontext einer von jeder sozialen Resonanz isolierten Überbaurevolte ist es nicht zufällig, daß die Sozialismus-Diskussion als Zielbestimmung gesellschaftlicher Emanzipation, als Untersuchung der nach ihrem Selbstverständnis sozialistischen Übergangsgesellschaften und als Auseinandersetzung mit den sozialistischkommunistischen Bewegungen in den kapitalistischen Ländern kaum in ihrem inneren politischen Zusammenhang geführt wird. Vielmehr dominiert die dogmatische Rezeption von Theorien, die romantische Übernahme anderer Gesellschaftsmodelle oder die Identifikation mit offiziellen Strömungen und Größen der Arbeiterbewegung. Auch die marxistische Diskussion ist davon nicht unberührt geblieben, indem entweder die Marxsche Theorie als Deduktionsmodell fungiert oder Realanalysen historistisch angefertigt 'werden, ohne die politisch-rationale Klärung der sozialistischen Ziele vorzunehmen. Man sehe sich hierzu nur die kürzlich im ,Argument $^{\text {" }}$ geführte Sozialismus-Debatte an (4), so springt einem der subjektiv gute Wille, überhaupt gemeinsam zu diskutieren, und zugleich die objektive Zerfahrenheit, die Diskussion um „gemeinsame“ Ziele zu führen, sofort in die Augen. Bahros

R. Bahro: Seibstinterview, in: ders., Eine Dokumentation, S. 56-73

3 . Eine kritische Darstellung der Geschichte der westdeutschen und internationalen Sozialismus-Diskussion wäre durchaus lohnend, um überhaupt den politisch-wissenschaftlichen Diskussions- und Problemstand zu rekonstruieren. Im Diskurs mit Bahro kann ich auf einzelne Positionen im folgenden nur sehr kursorisch eingehen. Das Argument, Hefte 98, 100, 102 und 105, Berlin, Karlsruhe $1976 \mathrm{f}$. 
Alternative könnte einen neuen Anstoß für eine alle Dimensionen der SozialismusDebatte integrierende und damit auf der politisch-wissenschaftlich angemessenen Ebene ablaufende Diskussion geben.

Obwohl sein Buch in aller Munde ist und vielfältig besprochen wird, ist der Anfang dieser Auseinandersetzung allerdings alles andere als ermutigend. Dies liegt weniger daran, daß Bahros Buch gerade seit einem halben Jahr erschienen ist, als an den angedeuteten eingefahrenen Denk- und Argumentationsstrukturen der westdeutschen Sozialismus-Diskussion. Statt Bahros geschichtsmaterialistische Theorie der sozialen Emanzipation zu rezipieren, statt seine von dieser emanzipatorischen Perspektive betriebene SU- und DDR-Analyse zu verfolgen, statt seine Strategie der kommunistischen Transformation für die osteuropäischen Länder und die darin enthaltene Strategie für ein sozialistisches Westeuropa und alle kapitalistischen Länder zur Kenntnis zu nehmen und seine Kritik an Marx, Engels, Lenin und der traditionellen Arbeiterbewegung ernstzunehmen, kurz: statt die wichtigsten Impulse seiner Sozialismusanalyse kritisch-produktiv aufzunehmen, wird Bahro lediglich als radikalsensationeller, womöglich liberal-demokratischer Kritiker des SED-Regimes vereinnahmt oder umgekehrt nur auf der inquisitorischen Ebene des DDR-Feinds behandelt, also beidesmal inhaltlich begrabeh.

Neben der wie ein Echo der DDR-Politik ertönenden Verurteilung Bahros durch die DKP-Presse sind selbst kritisch an der DKP orientierte Stellungnahmen wirklich skandalös. Im Kommentar J. Bischoffs (5) etwa wird nach ein paar aus dem theoretischen und historischen Zusammenhang herausgegriffenen Zitaten Bahro als , ïberzeugter Antimarxist" , als Vertreter eines „kleinbürgerlich-utopischen reaktionären Sozialismus“ und als Sprachrohr der angeblich orientierungslosen Linken in der BRD abgestempelt. Der ganze Kommentar ist an einer inhaltichen Auseinandersetzung schlicht nicht interessiert, sondern behandelt Bahro auf derselben Ebene wie die DDR-Behörden, ob er nämlich als Staatsfeind anzusehen sei. Nachdem man ihn auf diese Ebene abgedrängt und die Argumente für seine Verurteilung geliefert hat, kann man dann den staatsmännischen Rat an die DDR geben, daß ,staatliche Repression“ mehr schade ,als ein paar falsche Argumente reaktionärer Provenienz.

Nicht viel besser wenn auch gutwilliger ist leider auch die Stellungnahme W. Abendroths (6). Ohne wiederum auf den theoretischen Zusammenhang der Bahroschen Analyse einzugehen, wird ihm wenigstens zugestanden, einige Sonderanalysen der Mängel der sozialistischen Staaten richtig vorgenommen zu haben, allerdings ohne die entscheidenden exogenen Ursachen dieser Mängel zu benennen: den ständigen politischen und ideologischen Druck der imperialistischen Staaten auf die DDR, der die politische wie militärische Gewalt und die Konsumbedürfnisse der Massen eben notwendig mache. Doch auch hier steht von vornherein fest, daß

5 J. Bischoff: Bahro - eine Alternative?, in: Beiträge zum wissenschaftlichen Sozialismus, Heft 15, Hamburg 1978, S. 21-38

6 W. Abendroth: Weder Strategie noch - insgesamt - richtige Analyse, aber eine wichtige Quelle zum Problem des gegenwärtigen Entwicklungsstadiums des realen Sozialismus, in: Das Argument 107, Berlin, Karlsruhe 1978, S. 60-66 
Bahro mit der Veröffentlichung seiner Analyse objektiv gegen die Interessen der DDR und der westdeutschen Arbeiterbewegung versțoßen hat, nur subjektiv sei er weder Konterrevolutionär noch Gegner des Kommunismus. Wieder wird Bahro nur auf der gerichtlichen Ebene abgehandelt, diesmal aber aufgrund seines guten Willens für Freispruch plädiert.

Die bisher einzige - neben einigen Kommentaren - umfassend inhaltliche Auseinandersetzung ist die von E. Mandel (7). Auch er hält Bahros Alternative für das wichtigste theoretische Werk aus den sozialistischen Ländern seit Trotzkis Verratener Revolution, doch er beschränkt sich in seiner Rezeption Bahros allzusehr auf diejenigen Elemente seiner Analyse, die in seine eigene Theorie der sozialistischen Übergangsgesellschaften passen, also auf dessen Zurückführung sozialer Herrschaft auf die gesellschaftliche Arbeitsteilung, auf dessen Verurteilung der stalinistischen Bürokratie und die kommunistisch-internationale Dimension seiner Analyse; kritisiert Bahro jedoch vorschnell in denjenigen Elementen seiner Analyse, die nicht in seine Konzeption passen, also dessen Betonung der historischen Notwendigkeit der stalinistischen Bürokratie in einer Phase ursprünglicher Akkumulation, dessen Kritik an der traditionellen Arbeiterbewegung und dessen Bestimmung des Verhältnisses von gesellschaftlicher Arbeitsteilung und Staat. Obwohl Mandels Kritik inhaltlich wichtige Punkte trifft, halte ich diese Form der Kritik angesichts des gegenwärtigen Diskussionsstands für zu vorschnell, weil ohne genaue Rekonstruktion des geschichtstheoretischen Begründungszusammenhangs bei Bahro seine Analyse der sozialistischen Länder und seine Strategie einer kommunistischen Alternative nicht adäquat diskutiert und dann die darin enthaltene Kritik an trotzkistischen Positionen wie etwa an der Theorie der Deformation der sozialistischen Übergangsgesellschaft durch den Stalinismus oder an der Rätetheorie allzu unbesehen abgetan werden können.

Genug der Vorrede. Es ist die Absicht dieses Aufsatzes, die eingangs behauptete Bedeutung der Bahroschen Analyse für die westdeutsche Sozialismus-Diskussion herauszustellen. Dabei soll analog zur Einteilung des Bahroschen Werkes zunächst seine Geschichtstheorie sozialer Emanzipation, dann seine Kritik des real existierenden Sozialismus und schließlich Fragen seiner Bestimmung einer kommunistischen Strategie der Kulturrevolution behandelt werden. Angesichts des Standes der Bahro-Auseinandersetzung wird unter diesen Punkten die Rezeption der zentralen Argumentationslinien im Vordergrund stehen, um jeweils im Diskurs mit der westdeutschen Sozialismus-Diskussion einige zentrale Kritikpunkte zu benennen und umgekehrt die vorwärtstreibenden Anstöße herauszuarbeiten. Eine gegeben* falls ausführliche Kritik würde in diesem Zusammenhang nur zur breiten Darstellung der eigenen Position verleiten und damit von den Stärken der Bahroschen Alternative ablenken.

7 E. Mandel: Bahros Echo, in: ders., Kritik des Eurokommunismus, Revolutionäre Alternative oder neue Etappe in der Krise des Stalinismus?, Berlin 1978, S. 94-115 


\section{Die Geschichtstheorie sozialer Emanzipation}

Bahro nimmt die marxistisch-leninistische Weltanschauung in ihren Ursprüngen, in ihrem eigentlichen Begriffsinhalt, in ihrem Versprechen auf eine neuge Zivilisation beim Wort und hält sie der schlechten Wirklichkeit des real existierenden Sozialismus gegenüber. Er zielt nicht bloß auf die politischen Sünden der sozialistischen Länder, etwa auf die Unterdrückung der oppositionellen Intelligenz oder auf die konzertierte Aktion der Zerschlagung des Prager Frühlings, es geht ihm um die Grundstruktur des real existierenden Sozialismus. Er stellt unumwunden die abgrundtiefe Diskrepanz zwischen der Marx-Engelsschen Sozialismus- und Kommunismusbestimmung und den bestehenden Gesellschaftsverhältnissen in den sozialistischen Ländern fest (insb. S. 26ff.) . War für Marx und Engels ím Kommunismus und hatte entsprechend in der sozialistischen Übergangsgesellschaft als praxisleitende Orientierung zu gelten - Ware, Geld und Kapital aufgehoben, so ist wohl im real existierenden Sozialismus das Privateigentum durch das Staatseigentum ersetzt worden, aber Lohnarbeit, Warenproduktion und Geld existieren nach wie vor (Dokumentation, S. 10). War dort die Aufhebung der alten Arbeitsteilung die Grundlage der Aufhebung sozialer Herrschaft, so werden hier auf Basis dieser alten Arbeitsteilung und ihrer Rationalisierung die Produktivkräfte weiterentwickelt. Sollte nach Marx und Engels der Staat in die Gesellschaft zurückgenommen werden, so herrscht hier gerade umgekehrt eine allgewaltige und stetig expandierende Staatsmacht samt Parteiapparat und Bürokratie, in denen nicht einmal die bürgerlichen Freiheiten entwickelt, sondern liquidiert worden sind. War nach Marx und Engels die Verwirklichung des Kommunismus nur als internationale Tat der herrschenden Vöiker denkbar, so glaubt man hier lediglich in den nationalen Grenzen den Sozialismus errichten zu können. Kurzum der real existierende Sozialismus ist nur Fortsetzung des kapitalistischen Wegs in anderer Form (S. 7), nicht mehr als eine protosozialistische, im Larvenstadium sich befindende.sozialistische Gesellschaft wie der Kapitalismus auch (S. 25), ein Staatsmonopolismus (S. 45), in dem das Staatseigentum an den gesellschaftlichen Bedingungen der Produktion herrscht (S. 12), eine Vergesellschaftung in entfremdeter Form universeller Verstaatlichung (S. 25), in total entfremdeter Form (S. 44). Bahro bestreitet mithin jede strukturelle oder tendenzielle Identität zwischen dem Begriff des Sozialismus und Kommunismus bei Marx und Engels und der gesellschaftlichen Realität der sozialistischen Länder und bestreitet damit der herrschenden Staatsideologie jedes Recht, die bestehende Ordnung in diesen Ländern in die Marx-Engelsschen Kategorien der Aufhebung des Privateigentums im Sinne des Kommunismus einzupassen (S. 43).

Bahros Kritik am real existierenden Sozialismus ist eine grundsätzliche Kritik. Aber die festgestellte Diskrepanz zwischen kommunistischem Anspruch und kommunistischer Wirklichkeit ist keine moralische Verurteilung, sondern Ausgangspunkt der Frage nach ihrer geschichtsmaterialistischen Erklärung. Die Aufhebung. des Privateigentums stellt nach Bahro offenkundig nicht automatisch die Verwirklichung einer sozialistischen Gesellschaft her, die Ablösung des Privateigentums und die allgemeine Emanzipation fallen um eine ganze Epoche auseinander (S. 24). 
„Wenn der real existierende Sozialismus nicht die Aufhebung des kapitalistischen Privateigentums ist - was stellt er dann nach seinem innersten Wesen dar?" (S. 55) Bahro stellt also die Frage nach dem Wesen des real existierenden Sozialismus und will in Analogie zur Marxschen Kapitalanalyse die Anatomie, die inneren Bewegungsgesetze des real existierenden Sozialismus darstellen (S. 14).

Den Schlüssel für die Beantwortung dieser Frage findet Bahro im nichtkapitalistischen Weg der Industrialisierung, den nicht nur viele Länder der Dritten Welt, etwa Persien (S. 150), einschlagen, sondern auch die Sowjetunion durchlaufen hat und in den über die Hegemonie der Sowjetunion auch die anderen Länder Osteuropas mit einbezogen worden sind. Er ist unter dem Druck der entwickelten kapitalistischen Produktivkräfte und des kapitalistischen Weltmarkts eine industrielle Entwicklungsform, die die Dominanz des kapitalistischen Privateigentums umgeht und stattdessen auf den Staat „,als Zuchtmeister der Gesellschaft für ihre technische und soziale Modernisierung" zurückgreift (S. 149f.). Diese staatliche Organisation der Industrialisierung ist also einerseits Ausdruck der Unmöglichkeit unter entwickelten kapitalistischen Verhältnissen bei Strafe der Kolonialisierung überhaupt noch einen kapitalistischen Weg zu gehen und andererseits direktes Anknüpfen an die vor der Entstehung des Privateigentums existierende staatlich organisierte Klassengesellschaft. Bahro nennt diese Gesellschaftsform alte ökonomische Despotie und gibt damit der Marxschen Kategorie der asiatischen Produktionsweise eine Schlüsselrolle für das Verständnis der Genese der nichtkapitalistischen Industriegesellschaft. „Die Analyse führt zu einem allgemeinen Begriff des ,nichtkapitalistischen Weges', der die meisten nominell sozialistischen Länder einschließt, und auf die Suche nach dem Ursprung des nichtkapitalistischen Weges in der Hinterlassenschaft der sog. asiatischen Produktionsweise." (S. 15)

Im impliziten Gegensatz zur Stalinschen Kanonisierung der gesetzmäßigen Stufenfolge der fünf Formationen Urkommunismus, Sklaverei, Feudalismus, Kapitalismus, Sozialismus/Kommunismus (S. 72f.) definiert Bahro die asiatische Produktionsweise, bzw. die alte ökonomische Despotie als das in Form der archaischen Áckerbaugemeinde existierende Verbindungsglied zwischen der patriarchalischen Endphase der Urgesellschaft und den Klassengesellschaften Asiens (S. 80), und sie stellt für ihn die allgemeine Grundlage der zunehmend durchs Privateigentum bewegten Gesellschaftsformationen der Sklaverei, des Feudalismus und des Kapitalismus dar. Mit der Ablösung oder Umgehung des Privateigentums auf höherer industriegesellschaftlicher Stufenleiter kommt diese allgemeine Grundlage einer staatlich-despotischen Klassengesellschaft wieder zum Vorschein und bildet als nichtkapitalistische wie die kapitalistische Industriegesellschaft - und in diesem Sinne protosozialistisch (Dokumentation, S. 12f.) - die letzte Stufe vor dem Kommunismus. Die Geschichte stellt sich für Bahro so als doppelte Bewegung dar: „Das einstmạls ,vorwärts ' und nun ,rïckwärts “ zu durchschreitende Übergangsstadium zwischen Kommunismus und entwickelter Klassengesellschaft ist beide Male gekennzeichnet durch eine spezifische, unmittelbar aus der gesellschaftlichen Arbeitsteilung und Kooperation erwachsende Funktion des Staates. Verstaatlichte, nicht mehr gemeinschaftliche bzw. noch nicht vergesellschaftete Produktivkräfte machen 
das Charakteristische dieser beiden Epochen aus." (S. 79 f.) Hierzu gebraucht er das geotektonische Bild, in dem der Urkommunismus die primäre, die ökonomische Despotie die sekundäre und das Privateigentum die tertiäre Formation darstent und mit Beseitigung der tertiären, die tieferliegende sekundäre Formation zum Vorschein kommt und nun durch Abtragung der sekundären wieder die primäre Formation aufgedeckt werden müsse (Dokumentation, S. 22f.). Die ökonomische Despotie ist für Bahro genetisch und strukturell deshalb so wichtig für die Erklärung der Gesellschaftsverhältnisse der sozialistischen Länder, weil sich hier Klassenspaltung und Staatsdespotie auf Basis gesellschaftlicher Arbeitsteilung gleichsam in reiner, einfach-durchschaubarer Form ausbilden. An den altorientalischen Reichen, an Altchina, Indien und dem Inkareich (insb. S. 81 f.) zeigt Bahro immer wieder den wesentlichen Sachverhalt, daß sich diese Gesellschaften arbeitsteilig in Hand- und Kopfarbeit, in unmittelbare Produktion und leitende Tätigkeit, in gesellschaftlich subalterne und gesellschaftlich synthetische, in psychologisch unproduktive und psychologisch produktive Arbeit zergliedern, diese gesellschaftliche Arbeitsteilung somit die wesentliche Grundlage der staatlich organisierten Klassengesellschaft darstellt. Wenn auch der real existierende Sozialismus nicht einfach als strukturelle Analogie zu dieser ökonomischen Dispotie erklärt werden kann (S. 80), so bleibt allerdings auf der Grundlage des Industrialismus und entsprechender Vergesellschaftung der Produktion mit dieser zentralen Arbeitsteilung auch die Basis von Klassengesellschaft und Staatsdespotie erhalten. Weder die erheblich komplexere Arbeitsteilung und die damit verbundene komplexere Schichtstruktur noch die eminente Entwicklung der Produktivkraft und des Reichtums der Gesellschaft können verdecken, daß sich die Gesellschaft nach wie vor in Hand- und Kopfarbeit, schematisch-monotone und schöpferisch-vielfältige Tätigkeit, in ausführende und leitende Arbeit, in gesellschaftliche Subaltemität und gesellschaftliche Synthesis von ihrem sozialen Gehalt und ihren psychologischen Folgen her teilt. Zwei weitere archaische Rückstände hebt Bahro hervor: die Ausbeutung und Unterdrüickung der Frau und die Herrschaft der Stadt über das Land (S. 54).

Kommunismus als Aufhebung jeder Klassenstruktur und jeder über der Gesellschaft existenten Staatsmacht kann für Bahro folglich im Kern nichts anderes heiBen, als ihre Grundlage: die Subsumption der Individuen unter die gesellschaftliche Arbeitsteilung aufzuheben. Die objektive Möglichkeit dieser Aufhebung ist erst mit dem reifen kapitalistischen oder nicht kapitalistischen Industrialismus, mit der vollen Entfaltung der Produktivkräfte und entsprechend entwickelter Fähigkeiten der Menschen, mit differenzierter Arbeitsteilung und vergesellschafteter Produktion gegeben. Aber Möglichkeit heißt noch nicht Wirklichkeit. Die allgemeine soziale und individuelle Emanzipation steht und fällt mit der Aufhebung der Tennung von gesellschaftlicher Subalternität und gesellschaftlicher Synthesis. Im Kontext des entwickelten Industrialismus heißt das, daß die mit dem gesellschaftlichen Produktionsprozeß gegebene komplexe hierarchisch-vertikale Struktur der Technologie sich nicht mehr in soziale Ungleichheit und soziale Herrschaft umsetzt. Der Kern der Kritik an den Ländern des real existierenden Sozialismus besteht darin, trotz objektiver Möglichkeit der Aufhebung sozialer Herrschaft, diese lediglich bewußtlos 
wie die kapitalistischen Gesellschaften zu perpetuieren. Der Kern der Alternative zum real existierenden Sozialismus wie zu den kapitalistischen Gesellschaftsverhältnissen besteht in der praktisch-theoretischen Orientierung auf die allgemeine Emanzipation, nur diese emanzipatorische Orientierung und eine in sie eingebundene politische Strategie sind nach Bahro geschichtsmaterialistisch revolutionär.

Wie die Analyse und Kritik des real existierenden Sozialismus durchgeführt wird, aus welchen strategischen Elementen diese emanzipatorische Alternative besteht, davon wird noch im folgenden die Rede sein. Die skizzierten Argumentationsschritte Bahros mögen zunächst genügen, um sich ein Bild von den Grundlinien seiner Geschichtstheorie zu machen. Eine erste Gegenüberstellung zur westdeutschen Sozialismus-Diskussion wird nach Bedeutung und Kritik seines Ansatzes zu fragen haben.

Beginnen wir mit einigen allgemeinen kritischen Gesichtspunkten. Ich halte die Verallgemeinerung der Kategorie der asiatischen Produktionsweise gleichsam zur Universalie des Geschichtsprozesses der Menschheit von der Zeit nach dem Urkommunismus bis zur Zeit vor dem entwickelten Kommunismus für äußerst fragwürdig. Gerade die jüngsten Beiträge zur Thematik der asiatischen Produktionsweise (8) heben kritisch schon in Bezug auf Marx hervor, daß dieser auf Grundlage von inzwischen überholtem historischen Material in unzulässiger Weise die altorientalischen Reiche, das Osmanische Reich, Indien, China und teilweise Rußland unter diese Kategorie subsumiert habe; sie definiere gemeinschaftliches Eigentum an Grund und Boden, selbstgenügsame, Manufaktur und Ackerbau verbindende Dorfgemeinden und eine über ihnen existierende despotische Staatsmacht mit gegebenenfalls gesamtgesellschaftlich-ökonomischen Funktionen als eine gesellschaftliche Grundeinheit, sei aber in dieser Einheitlichkeit in den genannten Ländern gar nicht nachzuweisen und deshalb sehon bei Marx in falscher Form historisch zu weit gefaßt. Um so mehr gilt diese Kritik für die Universalisierung der asiatischen Produktionsweise durch Bahro.

Diese Kritik muß folglich auch auf die Kategorie des nichtkapitalistischen Wegs der Industrialisierung verlängert werden, die nach Bahro unter Ablösung oder Umgehung des Privateigentums indirekt oder direkt an die asiatische Produktionsweise anknüpft. Wenn die asiatische Produktionsweise in der Definition von Marx nur sehr begrenzte historische Gültigkeit hat und damit der Ubergang von vorindustriellen $\mathrm{zu}$ industriellen Gesellschaften in sehr viel komplexeren historischen Formen sich vollzieht, so ist die Bahrosche Definition aller nicht nach dem bekanntlich auch sehr unterschiedlichen kapitalistischen Entwicklungsmuster Westeuropas, der USA und Japans ablaufenden Industrialisierungsformen als formationell einheitli-

8 Vor allem G. Sofri: Über asiatische Produktionsweise, Frankfurt 1972; L. Krader: The Asiatic Mode of Production, Sources, development and critique in the writings of Karl Marx, Assen 1975; P. Anderson: Lineages of the Absolutist State, London 1974, S. $462-$ 549; und auch R. Lorenz: Die traditionale chinesische Gesellschaft, Eine Interpretation sowjetischer Forschungsergebnisse, in: ders. (Hg.), Umwälzung einer Gesellschaft, Zur Sozialgeschichte der chinesischen Revolution (1911 - 1949), Frankfurt 1977, S. 11-93 
cher nichtkapitalistischer Weg offenkundig ebenso überhistorisch. Die despotische Staatsform vieler unterentwickelter Länder kann sehr wohl aus ihrer geschichtlichen Rückständigkeit im Kontext eines entwickelteren kapitalistischen Weltmarkts erklärt werden, d.h. stellt eine spezifische Kombination unterschiedlich entwickelter kapitalistischer Verhältnisse und historisch sehr verschiedener vorkapitalistischer. Formationen dar. Die Kategorie des nichtkapitalistischen Wegs der Industrialisierung ist historisch zu unspezifisch und unterstellt zudem eine Unabhängigkeit zur kapitalistischen Produktionsweise und eine prinzipielle Andersartigkeit ihr gegenüber, die historisch nicht zutreffen.

Man wird überhaupt feststellen, daß Bahro im Rahmen seiner allgemeinen Geschichtstheorie keine konkret-historische Formationsanalyse betreibt, weder der asiatischen Produktionsweise noch der nichtkapitalistischen Form der Industrialisierung noch der unter der Kategorie des Privateigentums zusammengefaßten Formationen der Sklaverei, des Feudalismus oder des Kapitalismus, daß Bahros Geschichtstheorie gleichsam zu universal angesetzt ist. Dies wird auch noch an seiner SU- und DDR-Analyse zu prüfen sein. Doch unbeschadet dieser generellen Kritik heißt dies keineswegs, daß seine Geschichtstheorie deshalb in ihrer Allgemeinheit falsch wäre. Was Bahro an der asiatischen Produktionsweise herausstellt und was er eigentlich unter ihr versteht, ist vielmehr der grundlegende Sachverhalt der gesellschaftlichen Arbeitsteilung in unmittelbare Produzenten und gesellschaftliche Leitung, also eine staatlich regulierte Klassengesellschaft. Was Bahro an der nicht-kapitalistischen Industrialisierung herausarbeitet, ist, daß wiederum ganz allgemein diesmal auf industriegesellschaftlicher Grundlage der Sachverhalt der Arbeitsteilung, der Klassengesellschaft und ihrer gesamtgesellschaftlichen Organisation als Staat nach wie vor existiert. Unbeschadet also der Kritik, daß er in Verbindung von asiatischer Produktionsweise und nicht kapitalistischer Industrialisierung eine falsche historische Kontinuität konstruiert, knüpft er doch in allgemeiner Form an das Zentrum des Marx-Engelsschen historischen Materialismus an. War für Marx und Engels die kapitalistische Produktionsweise höchste und entwickeltste Stufe der Klassengesellschaft, die auf Basis ihrer zivilisatorischen Funktion der Vergesellschaftung der Menschen gerade die Voraussetzung für die Aufhebung von Klassengesellschaft und Klassenstaat darstellt, so insistiert Bahro vornehmlich gegenüber einem MarxismusLeninismus, der umstandslos in der Sowjetunion und den anderen sozialistischen Ländern eine im Sinne des historischen Materialismus nachkapitalistische Gesellschaftsformation sieht, darauf, daß Arbeitsteilung, Klassengesellschaft und Klassenstaat nach wie vor existieren und deshalb die soziale und individuelle Emanzipation der Menschen nach wie vor anstehen. Es wird sich zeigen, daß Bahro die Elemente der gesellschaftlichen Emanzipation auf Grundlage eines entwickelten Industrialismus wie der DDR-Gesellschaft noch erheblich konkreter faßt als Marx und Engels. Die wesentliche Bedeutung der Bahroschen Geschichtstheorie besteht darin, die Analyse des real existierenden Sozialismus in den Kontext des historischen Materialismus als Theorie der Bedingungen und Möglichkeit der gesellschaftlichen Emanzipation zu stellen und damit den geschíchtsmaterialistischen Maßstab für wissenschaftliche Analyse und politische Praxis erneut zu setzen. 
Dieser wesentliche Kern der Bahroschen Analyse mag der westdeutschen Sozialismus-Diskussion als Diskussion um das Ziel einer sozialistisch-kommunistischen Gesellschaft gegenübergestellt werden. Im . Vergleich zur Bahroschen Alternative vertrete ich die (vielleicht provokatorische) These, daß diese Zieldiskussion theoretisch kaum explizit, meist in der Übernahme tradierter Praxis- und Theorieformen der ,Arbeiterbewegung ${ }^{6}$ identifikatorisch oder die eigenen Erfahrungsdimensionen umstandslos projizierend, kurzum diffus geführt wird. Die frühe Diskussion über radikale Demokratie, Rätedemokratie und Selbstverwaltung, über Emanzipation und befreite Gesellschaft, über arternative sozialistische Übergangsgesellschaften wie China und Kuba drïckte zunächst nichts anderes aus, als daß die in Deutschland traditionellen sozialistisch-kommunistischen Oppositionsformen als Interpretationsmuster der internationalen Klassenkämpfe und vor allem der eigenen Überbaurevolte nicht mehr ausreichten. Der sozialdemokratische Sozialismus: die Verbindung von gesellschaftlicher und wirtschaftlicher Demokratie hatte sich zu sehr als reformistische Orientierung im Rahmen kapitalistischer Verhältnisse erwiesen, ebenso der kommunistische Sozialismus in Form der Verstaatlichung der Produktionsmittel als revisionistische Praxis der sozialistischen Länder und ihres verlängerten Arms, der DKP. Sozialismus hieß weder Reformismus noch Stalinismus. Eine Zielorientierung der eigenen Bewegung war nur in der Rückkehr zu den eigentlichen Bedeutungsgehalten von Kommunismus, Sozialismus und Demokratie möglich, oft unter Unterlegung der eigenen Praxisformen, oder geschah in Form der Übernahme der Modelle alternativer sozialistischer Übergangsgesellschaften und alternativer internationaler sozialistisch-kommunistischer Strömungen wie Anarchismus, Linkskommunismus oder Trotzkismus. Die Diskussion um die sozialistisch-kommunistische Zielsetzung wurde im Kostüm traditioneller Strömungen der Arbeiferbewegung geführt, allerdings mit beginnender Rezeption der Marxschen Theorie und mit ersten Versuchen realgeschichtlicher Bedingungsanalysen der Arbeiterbewegung und der sozialistischen Länder.

Solange die Bewegung im Fluß war und ihr realpolitischer Gehalt dominierte, waren die Übergänge zwischen diesen Positionen ebenso fließend und nicht in festen Grenzen erstarrt. Aber mit der Stagnation der Überbaurevolte wandelte sich dies. Einerseits kehrte man, wenn auch kritisch auf innerorganisatorische Änderung aus, in die real mächtigsten Oppositionsströmungen, in die SPD und DKP/SEW zurück oder gründete außerhalb dieser Parteien eigene Organisationen. Die Sozialismus-Debatte wurde damit politisch und moralisch entschieden. Sozialismus war nun eben selbstredend mit immanenter Kritik - der reale Sozialismus als verstaatlichte Planwirtschaft, Sozialismus war die im Rahmen der Sozialdemokratie durchsetzbare Verbindung von Sozialismus und Demokratie, Sozialismus hieß die Übernahme des Programms der IV. Internationale als Verbindung von gesellschaftlicher Planung und Rätedemokratie oder war schlicht die einmal sich an der Macht befindende eigene Organisation. Andererseits wurde die Sozialismus-Diskussion auf Basis der Marxschen Theorie und ihrer empirischen Anwendung weitergeführt, áber sie blieb nicht unberührt von der Stagnation der Bewegung und ihrem universitären Forum. Die Sozialismus-Diskussion war geprägt durch die Rezeption der Marxschen Theorie 
und des ihr immanenten Sozialismus- und Kommunismusbegriffs: Kommunismus bedeutete negativ Aufhebung der entfremdeten Arbeit, der Klassengesellschaft und des Staates, des Privateigentums und der kapitalistischen Produktionsweise durch die Arbeiterklasse, positiv hieß er Herstellung der Assoziation der freien Produzenten, einer bewußt geplanten Gesellschaft auf Grundlage der entfesselten Produktivkräfte und der Ökonomie der Zeit, Sozialismus bedeutete den sukzessiven Übergang zum Kommunismus.

Eine erste Schranke dieser Diskussion lag im Abstraktionsgrad der Marxschen Theorie selbst begründet. Die Marxsche Sozialismusbestimmung war aus der allgemeinen Negation der kapitalistischen Klassengesellschaft gewonnen, der aber in den proletarischen Tendenzen der 48er Revolution und der Kommune in Frankreich sowie in den Produktivgenossenschaften nur in Ansätzen eine reale historische Erfahrung entsprach. Sozialistische Bewegungen nach Marx und eben auch die eigenen Praxisformen und Zukunftsprojektionen konnten sich deshalb sehr leicht formell auf Marx berufen und sich selbst dadurch als marxistisch legitimieren. Eine zweite Schranke dieser Diskussion bestand in der Rezeption der Marxschen Theorie hauptsä́chlich als Kapitaltheorie. Dadurch gelang wohl eine präzise Fassung der von Marx formulierten allgemeinen Gesetze der kapitalistischen Produktionsweise, doch die von Marx im Rahmen des historischen Materialismus formulierte Bestimmung gesellschaftlicher Emanzipation wurde auf Formeln wie Aufhebung der Gesetze der kapitalistischen Produktionsweise, Assoziation der freien Produzenten, soziale Emanzipation oder geplante Gesellschaft verdünnt, oft noch in der mystisch-agnostizistischen, wenn auch gegenüber falschen Avantgardevorstellungen berechtigten, Form: die Befreiung der Arbeiterklasse ist das Werk der Arbeiterklasse selbst. Dadurch wurde der ableitungslogische Schluß erleichtert, daß eben irgendwie jede reale Bewegung der Arbeiterklasse und ihrer Interessenorganisationen und jede Übergangsgesellschaft mit sozialistischem Selbstverständnis eine reale Auflösung des Kapitalverhältnisses darstellte. Die kritische Dimension der Marxschen historisch-materialistischen Emanzipationstheorie ging verloren oder wurde erst gar nicht entdeckt.

Sofern man diesen Reduktionen der Marxschen Theorie nicht aufsaß und nun in weiterführenden Realanalysen die konkreten Gesellschaftsverhältnisse in den kapitalistischen und sozialistischen Ländern erklären und dadurch zur materialistischen Kritik an herrschenden Ideolggien kommen wollte, gelang wohl in ersten Ansätzen der empirisch-historische Nachvollzug der Kapitalismus- und Klassenentwicklung in der BRD wie in anderen kapitalistischen Ländern und die empirisch-historische Analyse der sozialistischen Gesellschaften in der SU, der DDR oder in China. Auch konnte damit die Kritik an Sozialdemokratie, Parteikommunismus und MarxismusLeninismus auf empirisch fundierteren Boden gestellt werden. Bei allen Fortschritten dieser marxistischen Diskussion drohte dennoch die historische Anwendung der Marxschen Theorie in objektivistisch-verdinglichte Analyse abzugleiten, die - verstärkt durch die ąkademisch naheliegende Orientierung auf Spezialanalysen - den kritischen Zusammenhang zur Sozialismus-Diskussion, d.h. zur Diskussion um Ziele, Formen und Bedingungen menschlicher Emanzipation nicht mehr thematisierte. Die empirisch-theoretischen Analysen der kapitalistischen Länder und der sozialisti- 
schen Übergangsgesellschaften zeigten wohl zunehmend genauer die konkreten Formen der ökonomischen Entwicklung, der sozialen und politischen Widersprüche und der darauf bezogenen staatlichen Interventionen auf, aber demonstrierten damit eigentlich nur negativ, daß diese Gesellschaften nicht die allgemein-menschliche Entwicklungsform darstellten und deshalb grundlegend geändert werden müßten. Die Frage, was positiv denn allgemein und konkret als emanzipatorische Alternafive in ihren Formen und Bedingungen anzusehen sei, wurde methodisch nicht mehr in die Realanalyse eingebracht und konnte deshalb als Antwort auch nicht aus ihr hervorgehen.

Was in der westdeutschen Diskussion meist als politische Moral und begriffliche Bestimmung, als heimliche Identifikation und Kritik, als Theorie und empirische Analyse auseinanderfällt, ist in Bahros Alternative als Geschichtstheorie sozialer Emanzipation, als Analyse und Kritik des real existierenden Sozialismus und als sozialistische Orientierung der politischen Praxis eindeutig vermittelt. Eben deswegen könnte sie Brennpunkt einer neu geführten Sozialismus-Diskussion sein, auch wenn man mit Bahro im einzelnen nicht übereinstimmt. An seiner Analyse und Kritik der Sowjetunion und der DDR werde ich das weiterhin zu zeigen versuchen.

\section{Die Analyse des real existierenden Sozialismus}

Es wurde hervorgehoben, daß Bahro im Rahmen seiner Geschichtstheorie die Gesellschaftsverhältnisse der Länder des real existierenden Sozialismus als Variante des nichtkapitalistischen Wegs der Industrialisierung bestimmt, der unter Ablösung des Privateigentums die gesellschaftliche Form der asiatischen Produktionsweise wieder aufnimmt und als staatlich organisierte Klassengesellschaft im gleichen Sinn wie die kapitalistischen Länder protosozialistisch ist, als damit die Bedingungen der Möglichkeit der gesellschaftlichen Emanzipation geschaffen sind. Die Aktualität dieser Möglichkeit ist für Bahro abhängig vom Entwicklungsgrad der Industrialisierung. Die Geschichte der Länder des real existierenden Sozialismus unterteilt er deshalb in drei Entwicklungsphasen: das vorrevolutionäre zaristische Rußland als nur peripher industrialisiertes Land, Oktoberrevolution und Stalinismus als Übergangsphase zur Industrialisierung und die Bildung der sozialistischen Länder durch die Ausweitung des sowjetischen Gesellschaftssystems auf Osteuropa und die nachstalinsche Ära als Phase der Industrialisierung. Die letzte Phase untersucht er dann hauptsächlich und ausführlich an den Gesellschaftsverhältnissen der DDR.

Die vorrevolutionären Gesellschaftsverhältnisse des zaristischen Rußlands faßt Bahro im wesentlichen als agrarische Despotie, d.h. als weitgehendes Agrarland auf der Grundlage der asiatischen Produktionsweise. In sie eingebettet existierten einerseits feudale Gesellschaftsverhältnisse, die auch durch die staatliche Bauernbefreiung noch lange nicht beseitigt waren, und andererseits kapitalistische Verhältnisse, die weitgehend aus den kapitalistisch-imperialistischen Ländern übernommen sich in den Städten konzentrierten. Feudalismus und Kapitalismus stellẹn so für Bahro lediglich periphere Elemente in einer dominant asiatischen Produktionsweise dar, der 
zaristische Staatsapparat kann deshalb auch nicht als primär absolutistischer Staat, sondern muß als orientalischer Staatsdespotismus begriffen werden (insbes. S. $103 \mathrm{ff}$.).

Die Oktoberrevolution als Resultat dieser zaristischen Gesellschaftsverhältnisse und des imperialistischen Weltkriegs ist für Bahro, da Sozialismus als Übergang zur allgemeinen Emanzipation nur auf Basis der Industrialisierung möglich ist, deshalb nicht eine im Kern sozialistische Revolution, sondern stellte den Beginn der nichtkapitalistischen Form der Industrialisierung Rußlands dar. ,Sie war und ist vor allem die erste antiimperialistische Revolution in einem trotz begonnener eigener kapitalistischer Entwicklung noch überwiegend vorkapitalistischen Land, mit halbfeudaler, halb ,asiatischer ${ }^{\circ}$ ökonomischer Sozialstruktur. Ihre Aufgabe war real nicht der Sozialismus, sondern die schnelle Entwicklung Rußlands auf einem nichtkapitalistischen Weg.“ (S. 58) Mit der Beseitigung der feudalen und kapitalistischen Elemente wurde jetzt nicht der Sozialismus, sondern die asiatische Produktionsweise auf höherer Stufe freigelegt. Die Entstehung des Sowjetstaats, die Verstaatlichung der Bauern- und Arbeiterbewegung, die Zentralisierung von Partei, Staat und Bürokratie in Form parteilicher Machtkämpfe und Terror, die Kollektivierung der Bauern und die Stalinsche Form der Industrialisierung verkörperten nichts anderes als die Kontinuität der asiatischen Produktionsweise auf sich industrialisierender Basis, die Leninsche und Stalinsche Form des Sowjetstaats war das despotische Werkzeug der ursprünglichen Akkumulation oder des Übergangs zur Industrialisierung, sie war der Überbau des nichtkapitalistischen Industrialisierungswegs (S. 116 f.). Da Rußland wie die Sowje tunion ein erheblich rückständiges Land darstellte, war der Stalinismus als industrielle Despotie historisch unvermeidlich und Alternativen grundsätzlich nicht möglich. Keine Fraktion der bolschewistischen Partei konnte diese historische Notwendigkeit umgehen. Die grundsätzliche Tragik der Bolschewiki rührte daher, daß sie eine sozialistische Gesellschaft aufzubauen glaubten, in Wirklichkeit aber Charaktermaske einer asiatisch-despotischen Entwicklungsform des nichtkapitalistischen Wegs der Industrialisierung waren. Wenn Bahro eine Alternative reflektiert (S. 137), dann die Möglichkeit, daß Lenin wie Mao länger gelebt hätte und vielleicht dadurch die letzten Scheußlichkeiten des Stalinschen Terrors vermieden worden wären. Doch sagt dies deutlich spürbar etwas über den Charakter der zugrundeliegenden gesellschaftlichen Verhältnisse, über die Notwendigkeit des Despotismus und die Zufälligkeit von Alternativen aus. Die historische Notwendigkeit des Stalinismus war aber für Bahro zugleich progressiv, da er, wenn auch auf anderem Weg als die Bourgeoisie, die Industrialisierung und damit die Basis des Sozialismus überhaupt erst einmal herstellte (S. 137).

Im Maße jedoch der Überwindung der gesellschaftlichen Rückständigkeit durch die Entwicklung der Industrialisierung verliert der asiatische Despotismus seine historische Schicksalshaftigkeit. Die Nachkriegsentwicklung der Sowjetunion ist ein Zeichen hierfür, aber alle Staatsreformen bleiben noch in dem überkommenen industriell-despotischen Rahmen. Die Kontinuität der Staatsdespotie erklärt sich nicht nur aus der nach wie vor gegebenen technologischen Überlegenheit der kapitalistischen Länder, nicht nur aus der skizzierten halbasiatischen Vergangenheit Rußlands und der prägenden Umbruchssituation des Oktober, sondern vornehmlich aus 
dem antagonistischen Charakter der Produktivkräfte selbst, d.h. aus ihrer arbeitsteiligen Organisation und dem daraus resultierenden Klassen- und Staatscharakter der gesellschaftlichen Verhältnisse (S.153 ff.). Die wesentlichen Strukturen dieser nichtkapitalistischen staatlich organisierten Klassengesellschaft auf der Grundlage eines entwickelten Industrialismus werden nun von Bahro zentral am Beispiel der DDR analysiert. Er untersucht dabei hauptsächlich die Form der gesellschaftlichen Planung und Leitung, die Schichtstruktur dieser Gesellschaft und ihre staatlich-parteiliche Bürokratie als Antriebsmechanismus.

Die DDR-Gesellschaft ist gegenüber der Sowjetunion eine noch entwickeltere Industriegesellschaft, deshalb ist die gesellschaftliche Form einer staatlichen Klassengesellschaft noch überholter, die Alterantive der allgemeinen Emanzipation noch aktueller. Vom Maßstab dieser geschichtsmaterialistischen emanzipatorischen Perspektive sind Klassen- und Schichtstruktur, Staat, Partei und Bürokratie sowie die gesellschaftliche Planung als deren Vermittlungsagentur wesentliche Elemente dieser nichtkapitalistischen staatlichen Klassengesellschaft und haben in dieser Form keinerlei sozialistisch-emanzipatorische Qualität.

Durch die Entwicklung der Produktivkräfte und die Vernichtung der überkommenen Klassengliederung ist eine durchgängig hierarchisch geschichtete Gesellschaft entstanden. Die Sozialstruktur ist gleichsam die subjektive Seite der hierarchischen Struktur der modernen Technologie (S. 192). „Es ist diese Hierarchie der Arbeitsfunktionen bzw. Bewußtseinsebenen, die in der qualifikationsabhängigen Schichtdifferenzierung der protosozialistischen Industriegesellschaft auf einem bestimmten historischen Niveau der gesellschaftlichen Arbeitsteilung festgeschrieben ist. Nicht die Differenzierung der Arbeitsfunktionen und ihrer Anforderungen schlechthin, erst die Unterordnung der Individuen erzeugt die soziale Schichtung und das bürokratische Phänomen." (S. 192) Erst dadurch also, daß sich die Gliederung des gesellschaftlichen Arbeitsprozesses in soziale Herrschaft umsetzt, entsteht die soziale Schichtung.

Zugleich ist diese Sozialstruktur nicht nur eine quantitative Staffelung sozialer Ungleichheit, sondern eingebunden in die grundsätzliche Klassenstruktur der protosozialistischen Industriegesellschaft, die Trennung von gesellschaftlich leitenden, synthetischen und gesellschaftlich ausführenden, subalternen Funktionen. Die Verstaatlichung und Bürokratisierung der Gesellschaft und ihre Vollzugsinstanzen Staatsapparat und Partei sind Ausdruck dieser grundsätzlichen Klassenspaltung. In der Partei vereinigen sich weltliche und geistliche Autorität in einer quasi-theokratischen Struktur, sie ist der Motor der Bürokratie, der Staatsapparat der Transmissionsriemen zur Gesellschaft (S. 286 ff.). Die gesellschaftliche Planung ist nichts anderes als die staatliche Vermittlungsagentur zwischen Gesellschaft und Bürokratie (S. 258). Weder mehr zentrale noch mehr dezentrale Form dieser Planung ändern etwas an ihrem grundsätzlich bürokratischen Charakter (S. 451 f.).

Die Bürokratie ist die gesellschaftliche Form, in der sich die Produktivkräfte entwickeln. Die kapitalistische Konkurrenz ist als Antriebsmechanismus weggefallen, die Arbeitsdisziplin deshalb geringer, die Bürokratie ist eigentlich nur das Werkzeug der einfachen Reproduktion (S. 266), aber das Selbsterhaltungsinteresse im 
Kontext der technologisch überlegenen kapitalistischen Länder zwingt dennoch zum ökonomischen Wachstum (S. 279). Das Einholen und Überholen der kapitalistischen Länder ist auf diesem Weg nicht möglich und wäre zudem nichts anderes als die Reproduktion einer staatlich regulierten Klassengesellschaft auf erweiterter industrieller Stufenleiter. Nur die radikale Alternative der allgemeinen Emanzipation und damit die Aufhebung von Bürokratie, Staatsapparat und Partei und die in sie eingebundene staatliche Planung auf der Grundlage der Aufhebung der.gesellschaftlichen Arbeitsteilung würde eine prinzipiell neue Entwicklungsmöglichkeit der menschlichen Gesellschaft in der DDR und den anderen nominell sozialistischen Ländern erlauben.

In welchen Schritten sich Bahro diese emanzipatorische Alternative denkt, werden wir noch zu betrachten haben. Die Rekonstruktion der wichtigsten Argumentationslinien der Bahroschen Analyse der Genese und Struktur der Länder des real existierenden Sozialismus zeigt zunächst einmal, in welchem untrennbaren $\mathrm{Zu}$ sammenhang Realanalyse der Gesellschaftsverhältnisse dieser Länder, ihre fundamentale Kritik und die geschichtsmaterialistische Theorie sozialer Emanzipation stehen. Dieser zentrale Punkt soll nun wieder im Vergleich mit der westdeutschen Sozialismus-Diskussion als Diskussion über den gesellschaftlichen Charakter der sozialistischen Länder herausgestellt werden.

Beginnen wir wiederum mit einigen allgemeinen kritischen Anmerkungen zur Bahroschen Analyse der sozialistischen Länder. Der Kernpunkt der bisherigen Kritik war, daß Bahro seine Geschichtstheorie auf einem zu allgemeinen Niveau hält, keine spezifisch-historische Formationsanalyse betreibt und hiermit zusammenhängend die asiatische Produktionsweise und den nichtkapitalistischen Weg der Industrialisierung unzutreffend verallgemeinert. An seiner Analyse des zaristischen Rußland zeigt sich dies daran, daß er in unbesehener Anknüpfung an Marx-Engelssche Formulierungen vom halbasiatischen Rußland Feudalismus und Kapitalismus im vorrevolutionären Rußland im Grunde als periphere Oberflächenphänomene einer von ihrer Grundstruktur her asiatischen Gesellschaft einstuft. Eine genauere Diskussion darüber, ob das zaristische Rußland primär asiatisch oder feudal und in welchem Sinne die Charakterisierung der russischen Entwicklung als halbasiatisch richtig oder falsch ist, steht im Grunde noch aus (9). Ich neige angesichts sowjetischer und westlicher Forschungsergebnisse zur russischen Geschichte und angesichts der angedeuteten Problematik einer zu allgemeinen Fassung der Kategorie der asiatischen Produktionsweise mit P. Anderson etwa (10) der Ansicht zu, daß es sich im

9 R. Dutschke: Versuch, Lenin auf die Füße zu stellen, Berlin 1974, hat in Anknüpfung an Marx und Engels, insb. anhand der inzwischen in deutscher Sprache veröffentlichten Marxschen Schrift: Die Geschichte der Geheimdiplomatie des 18. Jhdts., Berlin 1977, die Version des asiatischen Rußland und des asiatischen Kapitalismus vertreten. Bei B. Rabeh1: Marx und Lenin, Berlin 1973; ders., W. Spohn, U. Wolter: Halbheiten in der Überwindung des Leninismus, in: Probleme des Klassenkampfs 11/12; U. Wolter: Grundlaggen des Stalinismus, Berlin 1975 und in B. Rabehls Kommentar zur Marxschen Geheimdiplomatie wird dieser Streitpunkt offengelassen.

10 P. Anderson: Passages from Antiquity to Feudalism, London 1974 und ders.: Lineages 
Falle Rußlands um eine spezifische Variante des europäischen Feudalismus handelt. Die Despotie der zaristischen Staatsmacht läßt sich nämlich sehr wohl als extreme Form des absolutistischen Staats verstehen, in dem sich extrem rückständige feudale von innen und entwickelte kapitalistische Verhältnisse in Westeuropa kombinieren (11), und macht den Rückgriff auf die Tartarenherrschaft und eine hierauf basierende Kontinuität der russischen Geschichte nicht nötig. Bezogen auf die Oktoberrevolution bedeutet diese Kritik weiterhin, daß Bahro die antifeudal-sozialistischen Tendenzen der Bauernschaft und die antibürgerlich-sozialistischen Tendenzen der Arbeiterschaft allzusehr vor den Relikten einer hypostasierten asiatischen Produktionsweise und den Imperativen einer staatlich angeleiteten Industrialisierung zurücktreten läßt und hiermit diesen nichtkapitalistischen Weg kategoriell so prinzipialisiert, daß gesellschaftliche Formunterschiede und Alternativen einer nachzuholenden Industrialisierung, die für Rußland nachträglich spekulativ, für heute unterentwickelte Länder aber durchaus aktuell sind, ausgeschaltet werden.

In diesem Kontext muß auch seine Erklärung des Stalinismus als despotischer Überbau einer an die asiatische Produktionsweise anküpfenden nichtkapitalistischen Industrialisierung kritisch befragt werden. In historischer Kontinuität zur zaristischen Gesellschaft als Mischung von feudalen und kapitalistischen Gesellschaftsverhältnissen läßt sich der Stalinismus als Neuauflage dieser vorrevolutionären Gesellschafts- und absolutistischen Staatsform verstehen und zwar als Kombination eines höheren Niveaus der Entwicklung des kapitalistischen Weltmarkts und einer durch die Oktoberrevolution aufgebrochenen, aber nach wie vor extrem rückständigen Gesellschaft. Zwangskollektivierung, Zwangsarbeit, westlich induzierte und kopierte forcierte Industrialisierung und ihre Koordination durch die despotisch-staatliche Planung samt der subjektiven Seite des Massenterrors stellen die historisch-konkreten Vermittlungsformen dieser Kombination dar. Die Liberalisierung des Stalinismus nach dem 2. Weltkrieg, die Dezentralisierung der zentralen Planung im Zuge der Einführung des Neuen Systems der Planung und Leitung und der damit verbundenen stärkeren Orientierung und ${ }^{*}$ Abhängigwerdung der staatlichen Planung vom ,sozialistischen' Wertgesetz zeigt dann die wesentlich entwickeltere und komplexere Stufe der Produktivkräfte, aber zugleich die immer noch gegebene relative Rückständigkeit gegenüber den kapitalistischen Ländern und damit die Abhängigkeit und Einbindung der Sowjetunion in die kapitalistische Weltmarktkonkurrenz mit all ihren ökonomischen, militärischen und politischen Erscheinungsformen an. In einem solchen Incerpretationsrahmen der Sowjetunion von ihren je historisch inneren und äußeren Gesellschaftsbedingungen her (12) ist weder die Universalisierung der asiati-

of the Absolutist State, a. a. O. Vgl. auch die Sammelbände zur Feudalismusdiskussion: L. Kuchenbuch, B. Michael (Hg.), Feudalismus - Materialien zur Theorie und Geschichte, Frankfurt/M., Berlin, Wien 1977 und H. Wunder (Hg.), Feudalismus, München 1974 W. Spohn: Die technologische Abhängigkeit der SU vom Weltmarkt, Bericht und Kommentar zu einer empirischen Studie von A. C. Sutton, in: Probleme des Klassenkampfs 19/20/21, Berlin 1975, S. 225 ff.

12 Ibid, S. 255 ff. Vgl. auch U. Wolter: Einleitung zu ders. (Hg.), Die Linke Opposition in der SU 1923 - 1928, 1. Bd., Bẹrlin 1976, ebenso den Ansatz von H. Szlajfer: Nachzuho- 
schen Produktionsweise noch die Prinzipialisierung der nichtkapitalistischen Industriealisierung zur Erklärung dès Stalinismus nötig. Der Weiterexistenz und -entwicklung von Wertgese tz, Lohnarbeit, Geld- und Warenverhältnissen käme dann auch nicht wie bei Bahro eine nur marginale Bedeutung im Rahmen einer wesensmäßig nichtkapitalistischen Gesellschaftsform zu, sondern zeigten die reale Mächtigkeit kapitalistischer Verhältnisse wenngleich unter staatlicher Einbindung an, die eine Konvergenz zur Gesellschaftsform der kapitalistischen Länder, d.h. eine stärkere Freisetzung der Formen kapitalistischer Konkurrenz keineswegs ausschließt.

An dem Mangel einer historischen Spezifik der Gesellschaftsanalyse im Rahmen einer universalen Geschichtstheorie leidet auch die Bahrosche DDR-Analyse. Da die Gesellschaftsverhältnisse der DDR allgemein als - hier im Gegensatz zur Sowjetunion nicht als direkte sondern - indirekte Anknüpfung an die asiatische Produktionsweise und die nichtkaptialistische Form der Industrialisierung interpretiert werden, kann wohl matrialistisch-kritisch ihr grundsätzlicher Klassencharakter und ihre staatlich-bürokratische Organisation herausgestellt werden, aber der historisch spezifische gesellschaftliche Inhalt dieser staatlichen Klassengesellschaft wird dadurch nicht berücksichtigt. Weder die ökonomische und politische Abhängigkeit der DDR von der Sowjetunion und die spezifische Einbindung der RGW-Länder in den kaptialistischen Weltmarkt, noch die kapitalistisch-preußisch-faschistische Vergangenheit der DDR und ihre sozial und politisch widersprüchliche Geschichte erscheinen konstitutiv für die Analyse der DDR-Verhältnisse. Wie im Falle der Sowjetunion bleibt auch für die DDR allgemein-methodisch die Frage, ob diese Gesellschaften überhaupt methodisch analog zur Marxschen Kapitalanalyse als Gesellschaftsformationen mit eigenen allgemeinen Gesetzen gefaßt werden können, oder ob sie nicht in der angedeuteten Weise auf einer historisch-konkreteren Abstraktionsstufe als sich entwickelnde Kombinationsform, von innen und außen bestimmter unterschiedlicher Gesellschaftsverhältnisse begriffen werden müssen (13).

Wiederum unbeschadet dieser generellen Kritik, daß Bahro auf Grundlage seiner allgemeinen Geschichtstheorie weder eine historisch-spezifisch angemessene Analyse der asiatischen Produktionsweise und eines hypostasierten nichtkapitalistischen Wegs der Industrialisierung, noch der Gesellschaftsverhältnisse der Sowjetunion und der DDR vornimmt, hat die Bahrosche Analyse und Kritik des realen Sozialismus im Vergleich zur westdeutschen Diskussion des gesellschaftlichen Charakters dieser Länder den zentralen Vorzugg, daß sie in den expliziten Rahmen einer Theorie der sozialen Emanzipation gestellt ist, dadurch der Realanalyse ihren objek-

lende Entwicklung unter Bedingungen des Weltmarkts: das Beispiel der polnischen Entwicklung, in: Probleme des Klassenkampfs 27, Berlin 1977, S. 7 ff.

13 Methodisch entspricht dies der Einsicht, daß auch die nationale Entwicklungsgeschichte des Kapitalismus in einem Land nicht einfach als Derivat der allgemeinen Gesetze der kapitalistischen Produktionsweise gefaßt werden kann, sondern in seinen Besonderheiten sich nur aus den historisch tradierten, inneren und den internationalen, äußeren Bedingungen erklären läßt. Vgl. hierzu W. Spohn: Weltmarktkonkurrenz und Industrialisierung Deutschlands 1870 - 1914, Berlin 1977 
tivistisch-verdinglichten Charakter nimmt und die Kritik an diesen Ländern in eine emanzipatorische Perspektive einbindet. Sehen wir uns hierzu das Verhältnis von Realanalyse der sozialistischen Länder und der sozialistischen Zielbestimmung in der, durch die internationale marxistische Debatte erheblich geprägten, westdeutschen Diskussion etwas genauer an.

Jede Diskussion und Analyse der nominell sozialistischen Länder steht notwendig im Zusammenhang der Klärung der sozialistischen Ziele auf entwickelt-kapitalistischer Grundlage, weil die Sowjetunion und in ihrem Gefolge die anderen osteuropäischen Länder von ihrem Selbstverständnis her nachkapitalistische Gesellschaftsformationen sind. Im Unterschied zur bürgerlichen Geschichtstheorie, die in den entwickelten bürgerlichen Gesellschaften das Ende aller Geschichte und daher die osteuropäischen Länder auf abweichendem Wegletztlich auf dasselbe Geschichtsziel hin konvergieren sieht, ist jede marxistische Geschichtstheorie und -analyse vor die entscheidende Frage gestellt, ob diese Länder letzten Endes im Marxschen Sinne sozialistische Gesellschaftsformationen sind, oder ob sie es nicht sind. Sind sie es bei allen Besonderheiten und Übergangsschwierigkeiten, so muß dies bezogen auf die Bestimmung der eigenen sozialistischen Ziele notwendig heißen, daß sie strukturell die eigenen sozialistischen Perspektiven vorzeichnen. Sind sie es nicht, so muß auch eine Orientierung der eigenen sozialistischen Ziele an den gesellschaftlichen Verhältnissen dieser Länder fortfallen, diese in eine an den Auflösungsbedingungen der entwickelten kapitalistischen Gesellschaften gewonnene eigenständige Programmatik eingebunden sein. Dieser wesentliche Zusammenhang jeder Sozialismus-Diskussion wird bei Bahro zentral aufgenommen und eindeutig beantwortet, besteht in der internationalen Sozialismus-Diskussion mehr oder weniger deutlich, doch in der westdeutschen Sozialismus-Diskussion zerfällt er meist in eine diffuse Sozialismusbestimmung als Ziel sozialistischer Praxis und nicht explizit darauf bezogene Analysen der osteuropäischen Länder.

Die fundamentale Prämisse der offiziellen marxistisch-leninistischen Legitimationsideologie und der hieran in unterschiedlichem Maß orientierten kommunistischen Parteien ist, daß mit der Verstaatlichung des Eigentums an Produktionsmitteln und mit der staatlichen Planung der Sozialismus verwirklicht und die Errichtung des Kommunismus lediglich eine Frage des Entwicklungsgrads der Produktivkräfte sei (14). Der despotische Terror stellt in diesem Kontext nur einen subjektiven Fehler Stalins, die zunehmende Berüicksichtigung des Wertgesetzes in der staatlichen Planung lediglich eine Frage der ökonomischen Effektivität dar, beide tangieren den sozialistischen Grundcharakter der Sowjetökonomie nicht. Eine hieran orientierte kommunistische Perspektive in den kapitalistischen Ländern stellt sich entsprechend den Aufbau des Sozialismus als eine durch die kommunistische Partei angeleitete Staatsökonomie vor, auch wenn ein Úbergangsstadium der antimonopolistischen Demokratie zwischen Kapitalismus und Sozialismus dazwischengeschaltet ist. Bahros Kritik an dieser ideologischen Prämisse ist das Zentrum seiner Alternative, indem

14 Vgl. nur das Standardwerk: Lehrbuch der Politischen Ökonomie - Sozialismus, Berlin (DDR) 1972 
er zeigt, daß eine verstaatlichte und in diesem Rahmen planbare Ökonomie keineswegs soziale Herrschaft beseitigt und folglich auch eine politische Orientierung auf dieses Ziel nebulös, gegebenenfalls sogar Legitimationsfunktion für die Aufrechterhaltung von sozialer Herrschaft hat.

Diese Gleichsetzung von staatlicher Industrie und Planung mit Sozialismus ist aber nicht nur die entscheidende Prämisse der sowjetmarxistischen Legitimationsideologie, nicht nur der verschiedenen Fraktionen der Bolschewiki in den 20er Jahren (15), sondern auch vieler der sich auf die damit verbundenen theoretischen Positionen beziehenden marxistischen Kritiker. Das gilt etwa für die subjektivistische Kritik Elleinsteins an der Stalinschen Diktatur (16), für Medwedews Anklage der mangelnden Demokratisierung von Partei und Staat als Ursache des Stalinismus (17) oder für den Vorwurf der Überzentralisierung der staatlichen Planung und der fehlenden Demokratie durch Dobb (18). Ohne die Bedeutung dieser jeweiligen Kritik herunterzuspielen, zeichnet doch mit dem Akzeptieren der Identifikation der verstaatlichten Ökonomie mit Sozialismus das sowjetische Gesellschaftssystem, jetzt allerdings in demokratischeren Formen die eigene sozialistische Perspektive vor, wobei dieser Demokratisierung als Bedeutungsgehalt von der bürgerlich-parlamentarischen Demokratie bis hin zur sozialistischen Marktwirtschaft alles unterlegt wird. Bahro insistiert demgegenüber auf der historischen Zwangsläufigkeit, d.h. der nicht jederzeitigen politischen Realisierbarkeit der Demokratisierung und gibt vor allem der Demokratisierung einen klaren sozialen Inhalt, nämlich als gesellschaftliche Aufhebung der menschlichen Subalternität.

Gegenüber den skizzierten Vorstellungen einer demokratisierten Planwirtschaft, die letztlich im Rahmen der Sowjetökonomie als sozialistisches Leitbild verbleiben, sind die Definitionen der sowjetischen Gesellschaft als Übergangsgesellschaft zwischen Kapitalismus und Sozialismus und damit als Widerspruch zwischen zwei antagonistischen Produktionsweisen erheblich kritischer gegenüber dem real existierenden Sozialismus. Für Bettelheim (19) haben sich allerdings mit den ökonomischen Reformen die kapitalistischen Elemente wieder durchgesetzt und hat sich die Verwandlung des Sowjetstaates in eine Staatsbourgeoisie endgültig vollzogen. Für ihn ist Sozialismus wesentlich als staatliche Planung unter Aufhebung des Wertgesetzes bestimmt. Demgegenüber hält Mandel (20) in Fortführung der Trotzkischen Position an dem widersprüchlichen Charakter der Sowjetökonomie fest, da die staat-

15 Stellvertretend für die Hauptfraktionen und bei allen ökonomischen und politischen Differenzen N. Bucharin: Ökonomik der Transformationsperiode, Berlin 1971 und E. Preobraschenskij: Die Neue Ökonomik, Berlin 1971

16 J. Elleinstein: Geschichte des, Stalinismus', Hamburg/Berlin 1977

17 R. Medwedew: Die Wahrheit ist unsere Stärke, Frankfurt/M. 1973

18 Etwa in: C. Bettelheim, Kritik der Sowjetökonomie, Berlin 1969

19 C. Bettelheim: Ökonomisches Kalkïl und Eigentumsformen, Berlin 1972 und ders.: Die Klassenkämpfe in der UdSSR, 1. Bd., 1917 - 1923, Berlin 1975, insb. S. 15-51

20 E. Mandel: Zehn Thesen zur sozialökonomischen Gesetzmäßigkeit der Übergangsgesellschaft zwischen Kapitalismus und Sozialismus, in: P. Hennicke (Hg.), Probleme des Sozialismus und der Übergangsgesellschaften, Frankfurt/M., 1973, S. 15-37 und ders.: Marxistische Wirtschaftstheorie, Frankfurt 1967 
liche Planwirtschaft als Grundeigenschaft einer sozialistischen Gesellschaft noch nicht beseitigt ist. Die Deformationen der Sowjetgesellschaft, namentlich die WareGeld-Beziehungen und die Bürokratie führt er auf die kapitalistischen Relikte zurück, deren Beseitigung eine politische Revolution erfordert, in der Rätedemokratie und Selbstverwaltung wiederhergestellt werden. Beide Positionen würde Bahro nicht schlicht für falsch halten, aber er insistiert ihnen gegenüber darauf, daß weder eine bloße Rückkehr zu einer rein gebrauchswertorientierten Planung, noch eine politische Revolution gegen die Bürokratie ausreichen, den sozialistischen Übergangscharakter der osteuropäischen Länder wiederherzustellen, sondern daß das Zentrum einer sozialistischen Ưbergangsgesellschaft die allmähliche objektive und subjektive Aufhebung der gesellschaftlichen Arbeitsteilung ist, ohne die bürokratische Administration der gesellschaftlichen Produktion und Planung nach Kriterien des Wertgesetzes immer wieder notwendig auftreten (vgl. S. 453 f.).

Sehen diese Konzeptionen einer sozialistischen Ubergangsgesellschaft in der Sowjetunion wenigstens partiell oder temporal sozialistische Elemente verwirklicht, die auch Teil einer zukünftigen sozialistischen Gesellschaft in den kapitalistischen Ländern darstellen, so besagt die Bestimmung der sowjetischen Gesellschaft als Staatskapitalismus etwa bei Cliff (21) und Mattick (22) letztlich, daß die Sowjetökonomie kein prinzipiell anders geartetes Gesellschaftssystem als das der kapitalistischen Länder darstellt und deshalb überhaupt keine Orientierung für eine sozialistische Strategie in den kapitalistischen Ländern enthält. Stattdessen heißt Sozialismus, daß die Produzenten die Kontrolle von Produktion und Distribution selbst in die Hände nehmen (23). In der gleichen Richtung einer grundsätzlichen Ablehnung der sowje tischen Gesellschaft als Sozialismus geht schließlich, wenn auch viel unbestimmter ihre Definition als etatistische oder bürokratisch-kollektivistische Gesellschaft (24). Wenn auch in diesen Definitionen der nichtsozialistische Charakter der gesellschaftlichen Verhältnisse in Osteuropa feststeht, so geht Bahro über diese Positionen insofern eindeutig hinaus, als er nicht einfach negativ demonstriert, daß Sozialismus grundlegend anders sei und auf den Emanzipationskampf des Proletariats hớfft, sondern sehr genau die Elemente sozialer Herrschaft benennt, die bei der Verwirklichung des Sozialismus und der gesellschaftlichen Emanzipation beseitigt werden müssen.

Was in der internationalen Diskussion noch als Zusammenhang zwischen der Analyse der nominell sozialistischen Länder und der eigenen Sozialismuskonzeption mehr oder weniger explitit erscheint, ist in der westdeutschen Diskussion meist nur vage und implizitenthalten. Sieht man einmal von der nur dogmatischen Übernahme der internationalen Diskussion ab, so werden durchaus eigenständige kritische und empirische Analysen erstellt, die aber nur undeutlich politische Konsequenzen

21 T. Cliff: Staatskapitalismus in Rußland, Frankfurt/M. 1975

22 P. Mattick: Marx und Keynes, Die Grenzen des, gemischten Wirtschaftssystems', Frankfurt/M. 1971 , S. $288-347$

23 Ibid., S. 340

24 Etwa A. Carlo: Politische und ökonomische Struktur der UdSSR (1917 - 1975), Berlin 1972 
enthalten und formulieren. Auf der einen Seite stehen mehr historische Analysen wie etwa die Arbeiten zur Sowjetunion von R. Lorenz (25), G. Meyer (26), H. Haumann (27) oder P.W. Schulze (28) und zur DDR von D. Staritz (29), die aber den Bezug zur theoretischen Diskussion über den Charakter des Gesellschaftssystems der sozialistischen Länder kaum herstellen und deshalb auch nicht direkt zu einer Sozialismus-Debatte beitragen. Auf der anderen Seite stehen mehr begrifflich orientierte Studien, wie die von der Planungsdebatte ausgehenden Arbeiten von Altvater/Neusüß (30), R. Damus (31), H. U. Foerderreuther (32) oder die von der Lenindiskussion und historischen SU-Debatte ausgehenden Arbeiten von R. Dutschke (33), B. Rabehl, W. Spohn und U. Wolter (34) sowie U. Schmiederer (35), die teilweise die staatliche Planung der Sowjetunion als Element des Sozialismus übernehmen oder teilweise zu einer grundsätzlichen Kritik am Gesellschaftssystem der sozialistischen Länder kommen. In dieser wenig aufeinander bezogenen Diskussion um den gesellschaftlichen Charakter der sozialistischen Länder wird unter Rekurs auf die sehr abstrakten Marxschen Bestimmungen in der Realanalyse wiederum hauptsächlich implizit oder negativ ausgedrückt, was Sozialismus ist oder was er nicht ist, ganz zu schweigen von der Auseinandersetzung um eine politische Programmatik. Als Ausdruck dieser Diskussionssituation verfolge man nur im Vergleich zur - von der Manifesto-Gruppe organisierten - Konferenz in Venedig (36) die in ,links' geführte SU-Debatte (37), die sich in der Einschätzung der objektiven Tendenzen der Sowjetunion verliert, ohne auf irgendeine Weise den Bezug zur Klärung der eigenen politischen Perspek tive herzustellen.

Es geht mir nicht darum, diese Arbeiten und Diskussionsbeiträge in ihrer $\mathrm{Be}$ deutung zu verkennen, sondern darum, auf ihren absolut vorläufigen Charakter hinsichtlich der Klärung einer sozialistischen Perspektive in Westdeutschland und Westeuropa hinzuweisen. Demgegenüber macht Bahro die emanzipatorische Perspektive

25 R. Lorenz: Sozialgeschichte der Sowjetunion 1, 1917 - 1945, Frankfurt/M. 1976

26 G. Meyer: Studien zur sozialökonomischen Entwicklung Sowjetrußlands 1921 - 1923, Köln 1974

27 H. Hauptmann: Geschichte und Gesellschaftssystem der SU, Köln 1977

28 P. W. Schulze: Herrschaft und Klassen in der Sowjetgesellschaft, Die historischen Bedingungen des Stalinismus, Frankfurt/M. 1977

29 D. Staritz: Sozialismus in einem halben Land, Berlin 1976

30 E. Altvater/C. Neusüß: Bürokratische Herrschaft und gesellschaftliche Emanzipation, in: Neue Kritik 51/52, Frankfurt 1969

31 R. Damus: Entscheidungsstrukturen und Funktionsprobleme in der DDR-Wirtschaft, Frankfurt/M. 1973

32 H. U.Foerderreuther: Zur These vom objektiven Entwicklungscharakter des Sozialismus, in: Mehrwert 11, Berlin 1976

33 R. Dutschke: Versuch, Lenin auf die Füe zu stellen, a. a. O.

34 B. Rabehl: Marx und Lenin, a. a. O., ders., W. Spohn, U. Wolter: Halbheiten in der Überwindung des Leninismus, a. a. O., U. Wolter: Grundlagen des Stalinismus, a. a. $\mathbf{O}$.

35 Siehe die Beiträge in: E. Jahn ( $\mathrm{Hg}$.$) , Sozioökonomische Bedingungen der sowjetischen$ Außenpolitik, Frankfurt/M. 1975

36 Die Beiträge von Rossanda, Claudin, Magri, Trentin und Althusser sind abgedruckt in: Kritik 16, Berlin 1978

37 links, Nummern $45-47,50,52,53,57,84,86,87$, Offenbach $1973 \mathrm{ff}$. 
zum expliziten Ausgangspunkt seiner Realanalyse und kommt dadurch nicht nur zu einer erheblich radikaleren Kritik des ral existierenden Sozialismus, sondern resultieren aus seiner Analyse zugleich genauere strategische Bestimmungen dieser emanzipatorischen Alternative. Der materielle Grund für diesen Unterschied in der Sózialismusbestimmung zwischen Bahro und der westdeutschen Linken mag darin liegen, daß Bahro unter DDR-Bedingungen von vornherein in gesellschaftlich-synthetischer Perspektive zu denken gezwungen ist, während der Sozialismusbegriff der westdeutschen Linken unter kapitalistischen Verhältnissen sehr stark durch die zersplitterten Kämpfe und dadurch bedingte Praxisformen geprägt wird.

\section{Fragen sozialistisch kommunistischer Strategie}

Aufgrund seiner allgemeinen Geschichtstheorie sozialer Emanzipation und seiner Analyse des real existierenden Sozialismus entwirft Bahro eine sozialistisch-kommunistische Strategie, die kurz- und vor allem langfristig eine emanzipatorische Alternative für die nominell sozialistischen Länder umreißt, die aber in ihrer Spannwẹite mit gewissen Unterschieden auch für die kapitalistischen Länder gilt. Bahro räumt den möglicherweise utopischen Charakter dieses strategischen Entwurfs ein, hält aber gerade gegenüber dem verdinglichten Marxismus (S. 299) utopisches Denken für nötig, um überhaupt die Diskussion um eine Alternative zu beginnen. Wie seinerzeit R. Luxemburgs: Sozialismus oder Barbarei! spriçht er in existentialistischer Weise aus: „Die allgemeine Emanzipation ist heute die absolute Notwendigkeit, weil wir in dem blinden Spiel der subalternen Egoismen, in der Unsolidarität, dem Antagonismus der atomisierten, entfremdeten Individuen, Gruppen, Völker, Konglomerate aller Art immer schneller dem Punkt zueilen, an dem es keine Wiederkehr im Guten mehr gibt. Das muß man wissen, ehe man fragt, wie sie möglich sei." (S. 300)

Im Rahmen seiner Geschichtstheorie ist das Zentrum der Bahroschen Alternative der allgemeinen Emanzipation die Frage, wie die alte Arbeitsteilung, in welchen Elementen und Schritten sie aufgehoben werden kann. Mit Marx heißt das für Bahro, vor allen Dingen die Universalität der Aneignungstätigkeit für alle Individuen $\mathrm{zu}$ ermöglichen (S. $301 \mathrm{f}$.), eine Kulturrevolution, die die ganze subjektive Lebensform der Massen umwälzt (S. 304). Bahro behandelt dabei einerseits die Programmatik dieser Alternative, die Fragen der neuen Ökonomie, des Verhältnisses von sozialer und individueller Emanzipation und der gesellschaftlichen Demokratie umfaßt, andererseits das revolutionäre Potential dieser Alternative, die soziale Basis und ihre organisatorische Zusammenfassung in einer neuen Partei des Bundes der Kommunisten. Über den unmittelbaren ökonomischen Aktionsplan oder das Minimalprogramm hinaus, der die bürokratischen Privilegien beseitigt, Arbeitsnormung und Stücklohn abschafft, die Beteiligung aller an einfacher, ausführender Arbeit vorsieht und das Lohngefüge berichtigt (S. 458 ff.), muß es im Maximalprogramm der Kulturrevolution langfristig um die massenhafte Überwindung der Subalternität in 
Form der Aufhebung der gesellschaftlichen Arbeitsteilung, der Klassengliederung und der Bürokratie gehen. Hierzu gehört eine grundsätzliche Umverteilung der Arbeit (S. 326 ff.), die der Tendenz nach allen Menschen die ausführende und psychologisch unproduktive, aber doch notwendige Arbeit aufbürdet, dadurch allen Menschen die Möglichkeit leitender und psychologisch produktiver Arbeit ermöglicht, also die materielle Vermittlung von subalterner und synthetischer Tätigkeit in jedem einzelnen Individuum herstellt. Es geht, wie Bahro mit Marx sagt, um die soziale Evolution des menschlichen Wesens zu einem Ensemble durchgängig philosophisch-selbstbewußter Individuen (S.327). Diese setzt aber nicht nur die objektive Umverteilung der Arbeitsfunktionen voraus, sondern bedeutet auch die subjektive Befähigung vornehmlich zur synthetischen Arbeit, was die Hochschulausbildung mit polytechnischer und künstlerisch-philosophischer Erziehung (S. 334 ff.), die Sicherung der Bildungsfähigkeit und Lernmotivation durch kreative Lernprozesse (S. 344 ff.), die Organisation eines neuen Gemeinschaftslebens im Rahmen autonomer Gruppen (S. 347 ff.) und die Vergesellschaftung und Demokratisierung des sozialen Erkenntnis- und Entscheidungsprozesses durch allgemeine Kommunikation über soziale Alternativen (S. $357 \mathrm{ff}$.) mit einschließst.

Auf der Grundlage dieser allmählichen, objektiven und subjektiven, sozialen und individuellen Aufhebung der Arbeitsteilung wird auch die bürokratische Planung allmählich vergesellschaftet werden können. Die Kriterien dieser vergesellschafteten Planung werden grundsätzlich andere sein als die bloß quantitative Entwicklung der Produktivkräfte. Angesichts des gegenwärtigen Stands der Produktivität hält es Bahro nicht für sinnvoll, an der dem. Fortschrittsglauben des 19. Jhdts. verhafteten Marxschen Formel von der Entfesselung der Produktivkräfte im Sozialismus im Sinne eines sprunghaften Wachstums festzuhalten, sondern vielmehr eine Anderung der Entwicklung der Produktivkräfte vorzunehmen, die am Produktionsziel der reichen Individualität ausgerichtet ist. Im gleichen Sinne gegen die Marxsche Fassung des Verhältnisses der Reiche von Notwendigkeit und Freiheit formuliert ër, daß die Verkürzung des Arbeitstags nicht ausreicht, um die freie Entwicklung des Individuums zu gewährleisten, vielmehr muß die psychologisch unproduktive Arbeitszeit innerhalb der notwendigen Arbeitszeit verkürzt werden, mithin das Reich der Freiheit das Reich der Notwendigkeit durchdringen (S. 492 ff.). Er fordert entsprechend nicht nur eine Ökonomie der Zeit, sondern eine neue Ökonomie der Zeit, die die gesellschaftliche Zeitbilanz von der individuellen Zeitbilanz aus bestimmt (S. 496). Diese Ausrichtung der gesellschaftlichen Planung an der reichen Individualität wird einschließen eine qualitative Änderung der Gebrauchswerte (508 ff.), die Harmonisierung der Reproduktion auch in internationaler Perspektive, d. h. die Wiederherstellung des Gleichgewichts zwischen Mensch und Natur namentlich durch Primat der einfachen Reproduktion, durch radikale Senkung des Material- und Energieaufwands und durch Orientierung der Produkte auf funktionelle Qualität (S. 512 ff.) und wird bedeuten den Übergang von der Finanzplanung zur Planung nach Zeitäquivalenten (S. 517 ff.). Diese Vergesellschaftung der Planung schließlich impliziert die grundlegende soziale und politische Demokratisierung der Gesellschaft, deren Zentrum in jedem Fall die Aufhebung der alten Arbeitsteilung 
darstellt, aber weitere strukturelle Bedingungen ihrer Ausibung voraussetzt: Die Gesellschaft muß in Form von Kommunen als ökonomischen Einheiten organisiert sein, die wiederum in Formen realer Gemeinschaft untergliedert sind und damit die Aufhebung des Gegensatzes von Stadt und Land sowie die Entfunktionalisierung der Familie durch die Vergesellschaftung der Hausarbeit und der Kinderbetreuung möglich macht. Die Assoziation auf verschiedenen Ebenen stellt die Organisationsform der Gesellschaft dar, die die strukturellen Bedingungen der Demokratisierung und Vergesellschaftung der Planung gewährleisten (S. 522 ff.).

Wer soll der soziale Träger dieser emanzipatorischen Alternative mit den skizzierten strategischen Elementen im real existierenden Sozialismus und auch in den kapitalistischen Ländern sein? Bezogen auf die kapitalistischen Länder ist Bahro sehr skeptisch gegenüber der Arbeiterklasse und ihren verschiedenen traditionellen Interessenorganisationen. Die Gewerkschaften kommen für ihn über ein trade-unionistisches Bewußtsein nicht hinaus, die Sozialdemokratie ist zur Partei der neuen Spezialistenschichten geworden (S. 219 f.), die kommunistischen Parteien primär aus externen Gründen der Oktoberrevolution und der sowjetischen Entwicklung entstanden (S. 217 ff.), die Arbeiterklasse in ihren spontanen Kämpfen eher egalitär als Träger einer neuen Gesellschaftsordnung. Und in den sozialistischen Ländern besitzt die Arbeiterklasse keine anderen Organisationen als die, von denen sie beherrscht wird (S. 223). Das Industrieproletariat hat für Bahro nicht dieselbe welthistorische Mission wie bei Marx. Aufgrund des Wandels der Industriegesellschaft, der Veränderung des gesellschaftlichen Gesamtarbeiters und der damit verbundenen hierarchischen Schichtungsstruktur in den sozialistischen wie kapitalistischen Ländern wird das Industrieproletariat nur teilweise der Träger der allgemeinen Emanzipation sein. Die soziale Basis der Alternative geht durch alle Schichten der Gesellschaft hindurch, sie besteht in dem massenhaft vorhandenen, nur durch die gesellschaftlichen Institutionen und die kompensatorischen Bedürfnisse gebundenen, überschüssigen Bewußtsein, d.h. der mit der Industrialisierung akkumulierten Qualifikation und Bildung subjektiver Produktivkraft, die gegen die bisherige Form gesellschaftlicher Synthesis insgeheim oder offen rebelliert und auch eine alternative Form der gesellschaftlichen Synthesis prinzipiell möglich macht. Die revolutionäre Strategie muß sich deshalb ,auf ein ganz bestimmtes Kräfteverhältnis innerhalb des gesellschaftlichen Bewußtseins, genauer innerhalb der Gesamtmasse an akkumulierter Qualifikation, subjektiver Produktivkraft einstellen, auf das Kräfteverhältnis zwischen dem überschüssigen und dem absorbierten Bewußtsein. " (S. 373) Bahro geht mithin davon aus, daß quer durch alle Schichten , im Industrieproletariat wie im Apparat, đas überschüssige Bewußtsein mehr oder weniger absorbiert, mehr oder weniger rebellisch vorhanden ist und nur zielgerichtet auf eine emanzipatorische Alternative hin mobilisiert werden muß, um selbst massenhafte Faktizität zu werden. Der Mobilisator dieser Alternative ist die neue Partei des Bundes der Kommunisten, sie muß mit den traditionellen Formen der Arbeiterbewegung, insb. der Kaderpartei leninistischen Typs rigoros brechen, keine Sekte der Besserwissenden, kein Überstaat und keine gehorsame Armee sein, sie muß sich vielmehr als kollektiver Intellektueller organisieren, als Aufklärungsavantgarde das überschüssige Bewußt- 
sein auf die allgemeine Emanzipation hin vereinigen, koordinieren und ausrichten. „Die ideologische'Hegemonie zu erringen, heißt in allen Schichten und Gruppen der Gesellschaft die Vorherrschaft einer integralen. Verhaltenstendenz in der Perspektive der allgemeinen Emanzipation zu erreichen. Dazu muß sich die Partei statt als Überstaatsapparat als der kollektive Intellektuelle organisieren, der die Reflexion der ganzen Gesellschaft, ihre Bewußtheit über alle sozialen Entwicklungsprobleme vermittelt und der in sich selbst etwas von dem humanen Fortschritt vorwegnimmt, für den er arbeitet." (S. $430 \mathrm{f}$.)

Es ist in einer solchen skizzenartigen Rekonstruktion nicht möglich, die Fülle der Bahroschen Gedanken auszuschöpfen, doch mag deutlich geworden sein, wie Bahro aufgrund der zentralen Einsichten des historischen Materialismus, der industriegesellschaftlichen, ökonomischen, politischen und persönlichen Erfahrungswelt und den aus den Widersprüchen der Industriegesellschaft entstehenden sozialen und politischen Bewegungen in den sozialistischen wie kapitalistischen Länder versucht, eine integrale emanzipatorische Alternative zu entwickeln, die sich nicht von tradierten Organisationsformen und spontanen Protestformen abhängig macht, aber auch nicht ihre vom Maßstab der Bedingungen gesellschaftlicher Emanzipation her vorwärtstreibenden Elemente unterschlägt. Er ist Ketzer, aber er ist nicht Sektierer. Zum Abschluß soll die politische Bedeutung der Alternative für die osteuropäische Opposition und die westeuropäische Linke befragt werden.

Was die osteuropäische Opposition gegen die nachstalinschen Herrschaftsformen angeht, glaube ich, daß die zunächst intellektuelle Wirkung Bahros nicht hoch genug eingeschätzt werden kann. Trotz staatlicher Versuche, die Diskussion über Bahro erst gar nicht aufkommen zu lassen, wird doch längerfristig entscheidend sein, daß nicht ein Außenstehender, sondern ein Insider der kommunistischen Staatspar-* tei in äußerst radikaler und kJarer Art und Weise auf Basis des Marx-Engelsschen historischen Materialismus die Gesellschaftsverhältnisse der sozialistischen Länder kritisiert und in Negation dieser Verhältnisse eine Alternative - wie utopisch auch immer - entwirft. Er geht damit entschieden über die bisherige politisch-theoretische Beschränktheit der osteuropäischen Oppositionsbewegung hinaus. Auch wenn er Produkt der sozialen und politischen Widersprüche der osteuropäischen Länder ist und durchaus mit den einzelnen Oppositionsströmungen sympatisiert, verfängt er sich nicht in diesen Verhältnissen. Er ist weder identisch mit der Bürgerrechtsbewegung -- so kann Bahro etwa Solschenizyn als rückwärtsgewandt ablehnen, doch zugleich seine humanen Impulse aufgreifen - , noch zu verwechseln mit den oszillierenden Forderungen nach mehr Demokratie, sei 's des bürgerlichen Parlamentarismus oder sei 's der sozialistischen Marktwirtschaft, verfängt sich auch nicht in der Alternative mehr zentraler oder mehr dezentraler Planung oder in der nebulösen Vorstellung der Wiederherstellung der wahren Herrschaft der Arbeiterklasse. Er lehnt diese Forderungen nicht rundheraus ab, unterstïtzt sie sogar - kommt er doch etwa zur Überlegung, ob nicht die Herstellung kapitalistischer Verhältnisse einen gesellschaftlichen Fortschritt bedeuten würde, da sie wenigstens eine autonome Klassenentwicklung ermöglichen (S. 390) -; vielmehr zeigt er ihre politische Be- 
schränktheit und ihr falsches Bewußtsein, als ob diese Maßnahmen jeweils eine grundsätzliche Veränderung der gesellschaftlichen Verhältnisse bedeuteten. Er macht grundsätzlich klar, in welche Richtung überhaupt eine sozialistisch-kommunistische Umwälzung der gesellschaftlichen Verhältnisse zu gehen hat und dürfte dadurch zu einem theoretischen Kristallisationspunkt einer kommunistischen Opposition in Osteuropa werden.

Wenn ich die intellektuelle Bedeutung Bahros für die klärende Diskussion einer kommunistischen Opposition in Osteuropa für außerordentlich halte, so heißt das gleichzeitig keineswegs, daß seine Alternative auf dem von ihm vorgestellten Weg auch politisch unmittelbar virulent werden wird. Ein Hauptgesichtspunkt meiner kritischen Anmerkungen war, daß Bahro allzusehr auf der Ebene einer allgemeinen Geschichtstheorie verbleibt, und keine historisch-spezifische Formationsanalyse betreibt. Vor dem Maßstab allgemeiner Emanzipation zeigt Bahro unmißverständlich auf, daß die osteuropäischen Länder keine sozialistischen Übergangsgesellschaften sind, aber unterstellt zugleich, daß auch jeder anstehende Konflikt unzweideutig in die Richtung der emanzipatorischen Alternative gehen wird. Es sei mir gestattet anzumerken, daß Bahro hier doch seinen eigenen politisch-theoretischen Werdegang in die gesellschaftlichen Verhältnisse Osteuropas projiziert. Da wird einmal die politische Entwicklung in der CSSR 1968 doch allzusehr als Beweis der Aktualität der Alternative gedeutet (S. 362 ff.). Da wird des weiteren die Tatsache, daß die politische Initiative in der CSSR aus dem Parteiapparat selbst kam, dahin interpretiert, $\mathrm{da} ß$ es durchaus denkbar ist, die Alternative als Staatsreform durchzuführen, wenn nur eben die wirklich kommunistische Partei an der Macht wäre. Nur dort schließlich, wo der Apparat wie in der SU und der DDR zu sehr versteinert ist, könnte nur eine Spaltung der kommunistischen Staatspartei das überschüssige Bewußtsein mobilisieren. E. Mandel hat hier sehr zu Recht eingewandt, daß Bahro aufgrund seiner Analyse der Bürokratie und ihren materiellen Interessenbedingtheit unmöglich den Apparat als Ausgangspunkt der emanzipatorischen Alternative hinstellen könne. Wenn Bahro von seiner allgemeinen Geschichtstheorie auf die konkretere Ebene der spezifischen Tendenzen dieser Gesellschaftsformationen herunterginge, müßte er sich selbst fragen, ob nicht die staatlich-despotischen und kapitalistischen Tendenzen eine eminent realere Geschichtsmächtigkeit in diesen Ländern haben, sodaß selbst im günstigsten und vorrangigen Falle der politischen Demokratisierung Bahros kommunistischer Bund eine kleine politische Splittergruppe darstellen würde, aber keine unmittelbar gesellschaftlich reale politische Tendenz. Die theoretisch radikale Alternative Bahros wird sich nicht auf den sachten Wegen einer Erziehungsdiktatur, sondern nur in sozial und politisch entsprechend radikalen Konvulsionen vollziehen - eine Konsequenz, zu der Bahro allerdings gelegentlich selbst kommt.

Bezogen auf Westeuropa und auf die westeuropäische Linke hat E. Mandel ebenfalls verwundert auf die praktische Vorsichtigkeit Bahros aufmerksam gemacht, die auf die aufklärerische Wirkung seiner Alternative hofft und die Kämpfe der Arbeiterklasse, seien sie vom Maßstab allgemein menschlicher Emanzipation auch noch so beschränkt, allzu skeptisch negiert. Daß sich im Zuge der Industrialisierung der gesellschaftliche Gesamtarbeiter ganz erheblich verändert hat, und es 
entsprechend fatal wäre, das Proletariat mit der Industriearbeiterschaft gleichzusetzen, ist ohne weiteres zugegeben, insofern hat auch Bahros Kritik an einem im falschen Sinne orthodox-marxistischen Begriff der Arbeiterklasse durchaus ihren rationellen Kern. Doch wird Bahros Alternative sich hier nicht einfach über die Mobilisierung überschüssigen Bewußtseins durchsetzen oder ungünstigenfalls über die Erziehungsdiktatur des Kommunistischen Bundes zu verwirklichen sein, sondern setzt die Entwicklung des Klassenkampfs und die in seinem Kontext sich vollziehende inhaltliche Veränderung des Bewußtseins der Menschen voraus. Die theoretische Radikalität der Bahroschen Alternative erfordert ebenso die politische Radikalität der sozialen Umwälzung, ohne sie muß sie utopisch bleiben.

Trotz alledem wäre es aber falsch, Bahros Alternative die geschichtsmaterialistische Radikalität abzusprechen. Es fehlen ihr allerdings die historischen und politischen Vermittlungen. Ich habe zu zeigen versucht, daß gerade diese theoretische Radikalität einen entscheidenden Impuls für die westdeutsche Sozialismus-Diskussion in ihren verschiedenen Aspekten darstellen könnte. Bahro ist ohne Zweifel auch beeinflußt von dem Aufschwung und den Formen der antiautoritären und gntikapitalistischen Bewegung bis hin zur Entwicklung des Eurokommunismus in Westeuropa. Aber seine allgemeine Emanzipationstheorie verbietet es, daß er von irgendeiner linken Gruppe oder Theorie vereinnahmt wird. Wenn auch wiederum seine historische Erklärung der sozialdemokratischen und kommunistischen Parteien nicht weit reicht, so ist seine Kritik an ihren Sozialismusvorstellungen als staatlich-bürokratische und reformkapitalistische Gesellschaftsplanung eindeutig. Wenn auch Bahro den Eurokommunismus für einen entscheidenden Fortschritt hält und seine auf alle Gesellschaftsschichten gegründete Strategie sehr freundlich aufnimmt, so liegt seine Kritik an den Inhalten dieser Strategie: der Orientierung an der parlamentarischen Demokratie, an der ökonomisch und politisch unaufhaltsamen Evolution zum Sozialismus, an dem nationalen Aufbau dieses Sozialismus und an den nicht überwundenen stalinistischen Relikten auf der Hand. Aber auch umgekehrt zeigt er gegenüber den anarchistischen, syndikalistischen, linkskommunistischen und trotzkistischen Vorstellungen eines libertären Kommunismus, der Produktionskontrolle, der Selbstverwaltung und der Rätedemokratie, daß sie ohne die Lösung des Problems der zentralen Kontrolle der gesellschaftlichen Produktivkräfte auf Basis der Aufhebung der gesellschaftlichen Arbeitsteilung keine allgemeine, soziale und individuelle Emanzipation herstellen (S. $520 \mathrm{ff}$.).

Die Bedeutung Bahros liegt in- seiner allgemeinen Geschichtstheorie der Bedingungen und Möglichkeit der allgemeinen Emanzipation, in seiner an diesem Maßstab radikalen Kritik an den Gesellschaftsverhältnissen der osteuropäischen Länder und der Bestimmung einer emanzipatorischen Alternative in ihren zentralen Elementen. Die Kritik an Bahro wird sich auf seine fehlende historische und politische Konkretion und die daraus entstehenden problematischen realanalytischen und strategischen Bestimmungen konzentrieren. Auf diese Weise könnte er ein integraler Impuls für eine stagnierende Sozialismus-Diskussion sein. Voraussetzung wäre, auch wenn die objektiven Bedingungen nicht günstig sind, mit Bahro weder rómantisch noch denunziatorisch zu verfahren, sondern die Sozialismus-Diskussion im Bahroschen Geist zu führen. 